Erratum

\title{
Erratum to "Quadratus Lumborum Block as Sole, Homeostatic-Preserving Anesthetic for a Patient with Multiple System Atrophy Undergoing Open Inguinal Hernia Repair: A Case Report"
}

\author{
Luca La Colla (iD) and Rebecca Schroeder \\ Department of Anesthesiology, Duke University Medical Center, Durham, NC, USA \\ Correspondence should be addressed to Luca La Colla; lacolla.luca@gmail.com \\ Received 7 August 2018; Accepted 8 August 2018; Published 19 August 2018
}

Copyright (c) 2018 Luca La Colla and Rebecca Schroeder. This is an open access article distributed under the Creative Commons Attribution License, which permits unrestricted use, distribution, and reproduction in any medium, provided the original work is properly cited.

In the article titled "Quadratus Lumborum Block as Sole, Homeostatic-Preserving Anesthetic for a Patient with Multiple System Atrophy Undergoing Open Inguinal Hernia Repair: A Case Report" [1], the names of the authors were given incorrectly as M. D. Luca La Colla and R. M. D. Schroeder. The authors' names should have been written as Luca La Colla and Rebecca Schroeder. The revised authors' list is shown above.

\section{References}

[1] M. D. Luca La Colla and R. M. D. Schroeder, "Quadratus lumborum block as sole, homeostatic-preserving anesthetic for a patient with multiple system atrophy undergoing open inguinal hernia repair: a case report," Case Reports in Anesthesiology, vol. 2018, Article ID 7161860, 3 pages, 2018. 


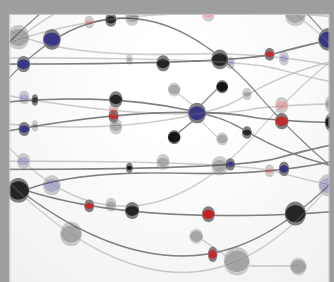

The Scientific World Journal
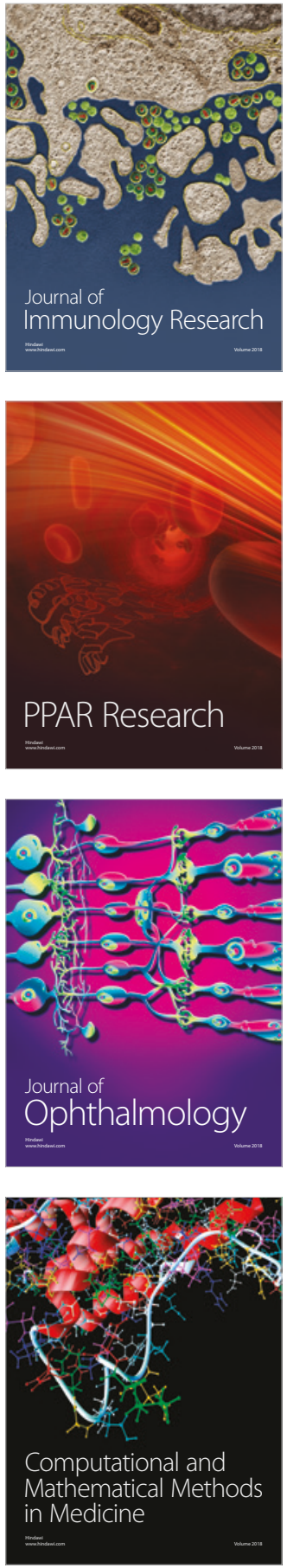

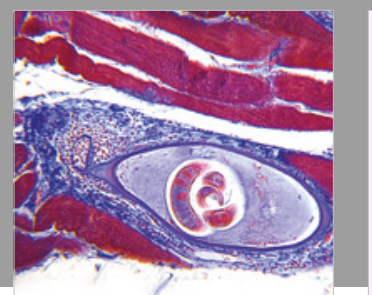

Gastroenterology Research and Practice

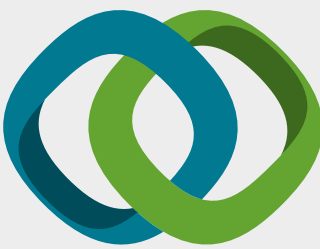

\section{Hindawi}

Submit your manuscripts at

www.hindawi.com
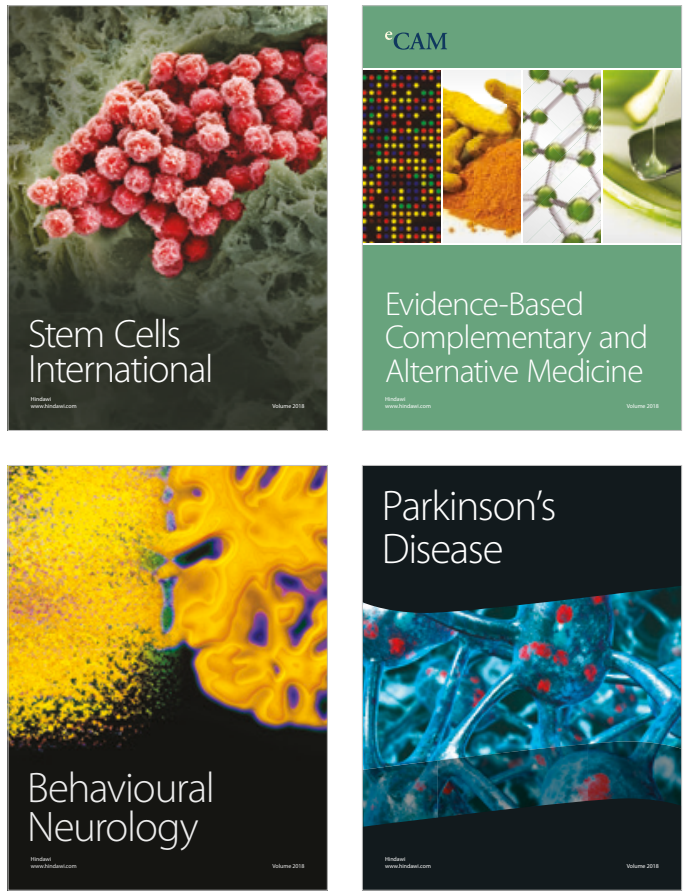

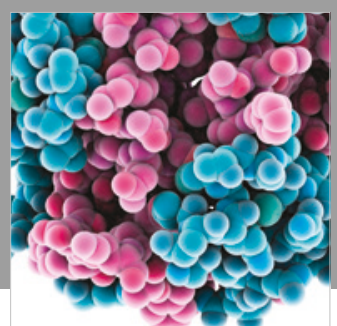

ournal of

Diabetes Research

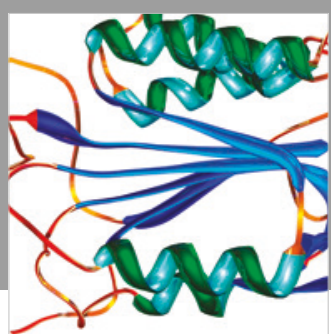

Disease Markers
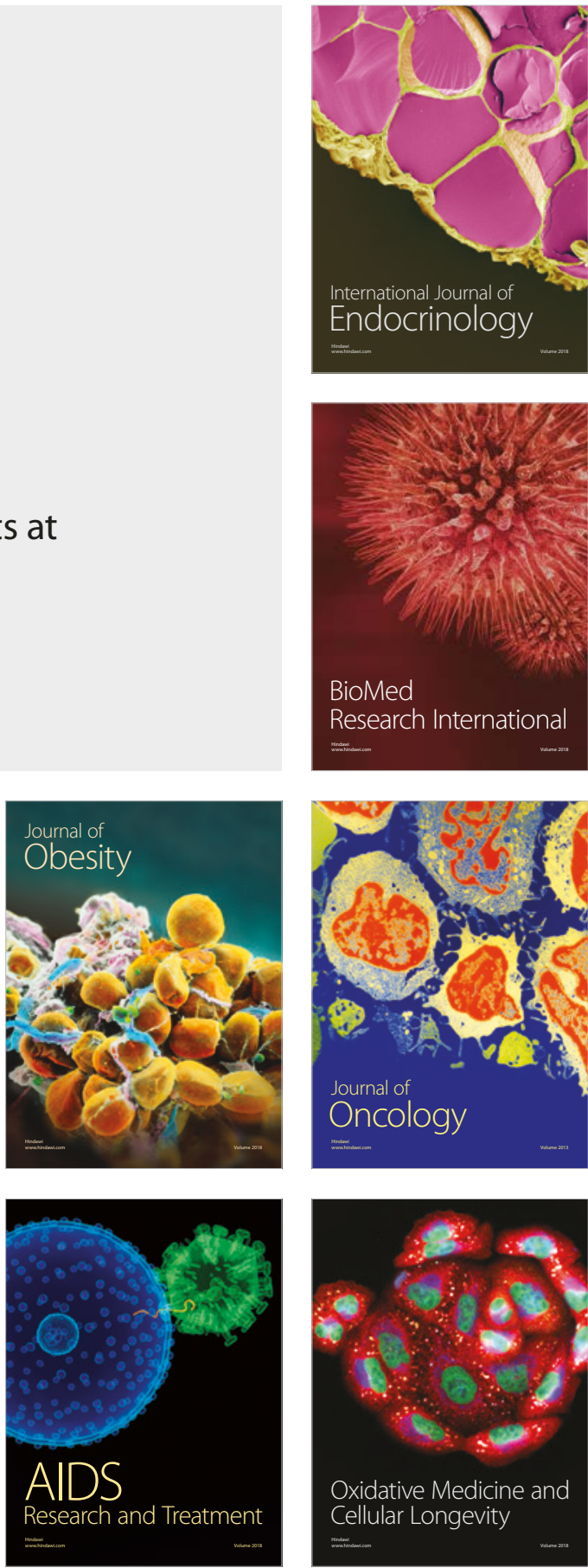